\title{
A STUDY ON SUBJECTIVE WELL-BEING OF YOUNG ADULTS
}

\author{
T. ASHA JYOTHI ${ }^{1}$, G. SWARUPA RANI ${ }^{2} \&$ M.SARADA DEVI ${ }^{3}$ \\ ${ }^{1,2}$ Research Scholar, Department of HDFS, C. H. Sc, Hyderabad, India \\ ${ }^{3}$ Professor, Department of HDFS, C. H. Sc, Hyderabad, India
}

\begin{abstract}
The objective of this investigation was, to study the subjective-well being among young adults, in terms of their age and gender. Samples of 60 young adults comprised an equal number of men and women belong to $21-35$ years were selected for the study. To study the subjective well-being, among young adults a scale was developed by Dr. H. Sell and Dr. R. Nagpal (1992). The results of the study indicated that, $2 / 3^{\text {rd }}$ of the young adults, i.e. both among men and women had a high level of subjective well-being. On the other hand, very few (10\%) of men and very no women were found in low level of subjective well-being. Further, the mean differences in subjective well-being, according to the age and gender indicated that, the age group 26-30 years had higher subjective well-being, than the other age groups. There were no significant differences in means of both men and women, in relation to total subjective well-being.
\end{abstract}

KEYWORDS: Subjective Well-Being, Well-Being, Life-Satisfaction \& Young Adults

Received: Aug 20, 2017; Accepted: Sep 06, 2017; Published: Sep 13, 2017; Paper Id.: IJESROCT20174

\section{INTRODUCTION}

The life experiences and perspectives of young people in the 21 st century differ greatly. About 87 percent of young women and men, living in developing countries face challenges brought about by limited and unequal access to resources, healthcare, education, training, and employment as well as economic, social and political opportunities. India accounted for a substantial share of world population. By 2010 , India accounted for $17.8 \%$ of the world population, recording an increase of $2.7 \%$ in its share, since 1970 . This growth is projected to continue and by 2030 , Indians would account for $17.97 \%$, of the global population.

Young adults being enthusiastic, vibrant, innovative and dynamic in nature, is the most important section of the population. Young adults show strong passion, motivation and will power, which also make them the most valuable human resource for fostering economic, cultural and political development of a nation. A country's ability and potential for growth is determined by the size of its productive population.

Subjective wellbeing (SWB), thought to comprise a cognitive-judgmental dimension reflecting life satisfaction and an emotional evaluation characterized by positive and negative effect, has been linked to important outcomes. For example, research has demonstrated that happy individuals tend to have larger social rewards, better work outcomes, and greater coping abilities, better immune systems, to be more cooperative, pro-social, and charitable and to live longer than individuals who are not happy (Lyubomirsky et al. 2005).

Subjective well-being measures are designed to capture information about, how people experience their lives. They are based on individuals' self-reports, and common measures include questions about whether people feel satisfied, content and fulfilled in their lives overall, as well as a range of more day-to-day emotions, such as 
happiness, worry, depression, and sadness. If applied and interpreted carefully, subjective well-being measures can play an important role in complementing quality of life measures, based on people's objective life circumstances. Subjective wellbeing indicators provide the kind of direct measure of outcomes, that is increasingly seen as a desirable way to evaluate and determine policy (New Economics Foundation; 2009).

\section{Significance of Studying Subjective Well-Being among Young Adults}

In general, people's own opinion about their lives, and the quality of their day-to-day experiences, can play an important part in building up a picture of the well-being of the population. There are several reasons, why it can be helpful to use subjective well-being as a complement to other more objective measures of life circumstances:

- People's feelings about life, and their emotional states, can be seen as intrinsically important for their quality of life. Someone who is deeply unsatisfied with their life, who feels that their life has no meaning or purpose, or who experiences extreme depression and sadness is unlikely to be viewed as having a good quality of life (Dolan and Metcalfe (2011). While, it is clear that, people are sometimes willing to trade short-term feelings of happiness for other outcomes of value, it is also clear that people regard subjective well-being as an important outcome in its own right (ONS UK, 2011).

- Subjective well-being measures seem to be able capture aspects of life that, other more conventional economic indicators can fail to highlight. For example, the importance of mental health, the quality of a person's relationships, and feelings of freedom, autonomy and trust. Rising economic prosperity is a very important mechanism for improving people's well-being, but rising GDP alone does not always guarantee political stability, social harmony, or increasing happiness (Grimes, A. Et al. 2012)..

- There is evidence to suggest that, low subjective well-being can be a precursor to other issues and problems in people's lives, while, high levels of subjective well-being have been associated with a range of positive life outcomes. Subjective well-being has been prospectively linked to objective well-being outcomes, in fields such as health, experiences of work, and aspects of social connections (De Neve, Diener, Tay and Xuereb (2013); Diener and Chan (2011); Lyubomirsky, King and Diener (2005)).

Because of the positive outcomes, associated with SWB, it is important to understand the factors that contribute to well-being. With this aim, the following objectives were selected and studied.

\section{OBJECTIVES}

- To study the subjective well-being of young adults

- $\quad$ To study the differences in subjective well-being of young adults

\section{METHODOLOGY}

\section{Sampling Criteria}

Young adult men and women, between the age group of 21-35 years, were selected for the study.

\section{Sampling Technique}

Purposive sampling technique was adopted for the study (since the persons who were young adults belong to the 
age group of 21-35 years were selected).

\section{Sample Size}

A total of 60 young adults, consists an equal number of men and women were selected for the study.

\section{Measurement Tools}

The subjective well-being of young adults was measured by using the subjective well-being scale developed by Dr. H. Sell and Dr. R. Nagpal (1992).

This scale consists of 11 components. (General well-being, positive effect, Expectation-achieve congruence, Confidence in coping, Transcendence, Family group support, Social support, Primary group concern, Inadequate mental mastery, Perceived ill-health, Deficiency in social contacts, General well-being).

\section{RESULTS}

Table 1: Distribution of Respondents Based on the Subjective Well-Being

\begin{tabular}{|c|l|c|c|c|c|c|c|}
\hline \multirow{2}{*}{ S. No } & \multirow{2}{*}{ Subjective Well-Being (Score Category) } & \multicolumn{2}{|c|}{ Men } & \multicolumn{3}{|c|}{ Women } & \multicolumn{2}{|c|}{ Total } \\
\cline { 3 - 8 } & & $\mathbf{N}$ & $\mathbf{\%}$ & $\mathbf{N}$ & $\boldsymbol{\%}$ & $\mathbf{N}$ & $\boldsymbol{\%}$ \\
\hline 1 & High & 19 & 63 & 20 & 67 & 39 & 65 \\
\hline 2 & Moderate & 8 & 27 & 10 & 33 & 18 & 30 \\
\hline 3 & Low & 3 & 10 & 0 & 0 & 3 & 5 \\
\hline
\end{tabular}

The results showed that, $2 / 3^{\text {rd }}$ of the young adults, i.e., both among men and women had a high level of subjective well-being. On the other hand, very few (10\%) of men and very no women were found in low level of subjective wellbeing. It seem from the results that, compared to men, women had both- high and moderate level of subjective well-being. The reasons attributing to this situation could be, due to the differences in life satisfaction level, receiving support from parents and women might be maintaining a close relationship with their family members, than men. All these reasons might have created the differences in subjective well-being of men and women.

Table 2: Mean Differences in Components of Subjective Well-Being Based on Age Group

\begin{tabular}{|c|c|c|c|c|c|}
\hline S. No & Dimension & Age Group & Means & F Value & Pr>F \\
\hline \multirow{3}{*}{1} & \multirow{3}{*}{ General well-being, positive affect } & 21-25 years & 6.1 & \multirow{3}{*}{$0.198 \mathrm{NS}$} & \multirow{3}{*}{0.8206} \\
\hline & & 26-30 years & 6.4 & & \\
\hline & & 31-35 years & 6 & & \\
\hline \multirow{3}{*}{2} & \multirow{3}{*}{ Expectation-achievement congruence } & $21-25$ years & 5.38 & \multirow{3}{*}{$3.014 *$} & \multirow{3}{*}{0.0569} \\
\hline & & $26-30$ years & 6.28 & & \\
\hline & & $31-35$ years & 5.22 & & \\
\hline \multirow{3}{*}{3} & \multirow{3}{*}{ Confidence in coping } & 21-25 years & 6.38 & \multirow{3}{*}{$5.040 * *$} & \multirow{3}{*}{0.0096} \\
\hline & & 26-30 years & 7.24 & & \\
\hline & & $31-35$ years & 5.77 & & \\
\hline \multirow{3}{*}{4} & \multirow{3}{*}{ Transcendence } & $21-25$ years & 6.5 & \multirow{3}{*}{$1.323 \mathrm{NS}$} & \multirow{3}{*}{0.2741} \\
\hline & & 26-30 years & 6.44 & & \\
\hline & & $31-35$ years & 5.55 & & \\
\hline \multirow{3}{*}{5} & \multirow{3}{*}{ Family group Support } & $21-25$ years & 7.65 & \multirow{3}{*}{$3.870 *$} & \multirow{3}{*}{0.0265} \\
\hline & & $26-30$ years & 7.28 & & \\
\hline & & $31-35$ years & 6 & & \\
\hline \multirow{3}{*}{6} & \multirow{3}{*}{ Social support } & $21-25$ years & 6.8 & \multirow{3}{*}{$2.687 *$} & \multirow{3}{*}{0.0766} \\
\hline & & 26-30 years & 6.28 & & \\
\hline & & $31-35$ years & 5.55 & & \\
\hline
\end{tabular}




\begin{tabular}{|c|c|c|c|c|c|}
\hline \multicolumn{6}{|c|}{ Table 2: Contd,. } \\
\hline \multirow{3}{*}{7} & \multirow{3}{*}{ Primary group concern } & $21-25$ years & 4.03 & \multirow{3}{*}{$1.941 \mathrm{NS}$} & \multirow{3}{*}{0.1529} \\
\hline & & 26-30 years & 4.4 & & \\
\hline & & $31-35$ years & 5.77 & & \\
\hline \multirow{3}{*}{8} & \multirow{3}{*}{ Inadequate mental mastery } & $21-25$ years & 16.5 & \multirow{3}{*}{$3.409 *$} & \multirow{3}{*}{0.0399} \\
\hline & & $26-30$ years & 14.8 & & \\
\hline & & 31-35 years & 13.6 & & \\
\hline \multirow{3}{*}{9} & \multirow{3}{*}{ Perceived ill-health } & $21-25$ years & 12.9 & \multirow{3}{*}{$0.465 \mathrm{NS}$} & \multirow{3}{*}{0.6300} \\
\hline & & 26-30 years & 13.6 & & \\
\hline & & $31-35$ years & 13.4 & & \\
\hline \multirow{3}{*}{10} & \multirow{3}{*}{ Deficiency in social contacts } & 21-25 years & 7.07 & \multirow{3}{*}{$2.086 \mathrm{NS}$} & \multirow{3}{*}{0.1335} \\
\hline & & $26-30$ years & 6.24 & & \\
\hline & & $31-35$ years & 6 & & \\
\hline \multirow{6}{*}{11} & \multirow{3}{*}{ General well-being-negative affect } & $21-25$ years & 7.4 & \multirow{3}{*}{$0.661 \mathrm{NS}$} & \multirow{3}{*}{0.5201} \\
\hline & & $26-30$ years & 7 & & \\
\hline & & $31-35$ years & 6.7 & & \\
\hline & \multirow{3}{*}{ Total SWB } & 21-25 years & 90.3 & \multirow{3}{*}{$3.158 *$} & \multirow{3}{*}{0.0777} \\
\hline & & $26-30$ years & 91 & & \\
\hline & & $31-35$ years & 80.2 & & \\
\hline
\end{tabular}

The above table gives the details of the differences, in mean scores of subjective well-being, arranged according to the age groups. It was found from the table that, there were age wise significant differences in mean scores of expectation-achievement congruence, confidence in coping, family group support, social support and inadequate mental mastery.

On the dimension of expectation-achievement congruence and confidence in coping, 26-30 years age group had a higher mean score, followed by 21-25 years and 31-35 years age group. It means, the older age group adults had a high mean score than the younger age group (21-25 years). This might be due to the reasons that, the older age group adults might be finished their education, might settled in their careers than the younger age group subjects (21-25 years). This might have helped them to have better performance on above stated components.

On the dimension of family group support, social support and inadequate mental mastery 20-25years age group had a higher mean score, followed by 26-30 and 31-35 years age group. The reason could be, they are in their final stage of education and few of them are going to establish a new career, and entering into new jobs at this stage. This particular group adult may undergo lot of stress, because they want to settle in a better career, due to this they may have received more family and social support.

The older age group adults, such as 26-30 years and 31-35 year had less mean score on these components. It indicates they were better able to manage on their own above stated components. Because, as age increases, there also increases in awareness levels with better consciousness about their own self and exposure to the events of life, the older age group adults' subjective well-being on these components was good.

Table 3: Mean Differences in Dim of Subjective Well-Being Based on Gender

\begin{tabular}{|c|c|c|c|c|c|}
\hline S. No & Dimension & Age Group & Means & F Value & Pr $>\mathbf{F}$ \\
\hline \multirow{2}{*}{1} & \multirow{2}{*}{ General well-being, positive affect } & Male & 9.2 & \multirow{2}{*}{$15.9 * *$} & \multirow{2}{*}{0.0001} \\
\hline & & Female & 6.2 & & \\
\hline \multirow{2}{*}{2} & \multirow{2}{*}{ Expectation-achievement congruence } & Male & 8.2 & \multirow{2}{*}{$5.68 *$} & \multirow{2}{*}{0.0204} \\
\hline & & Female & 6.6 & & \\
\hline \multirow{2}{*}{3} & \multirow{2}{*}{ Confidence in coping } & Male & 6.4 & \multirow{2}{*}{$4.59 *$} & \multirow{2}{*}{0.0362} \\
\hline & & Female & 7.7 & & \\
\hline
\end{tabular}




\begin{tabular}{|c|c|c|c|c|c|}
\hline \multicolumn{6}{|c|}{ Table 3: Contd,. } \\
\hline \multirow{2}{*}{4} & \multirow{2}{*}{ Transcendence } & Male & 6.36 & \multirow{2}{*}{$0.0266 \mathrm{NS}$} & \multirow{2}{*}{0.8709} \\
\hline & & Female & 6.3 & & \\
\hline \multirow{2}{*}{5} & \multirow{2}{*}{ Family group Support } & Male & 7.03 & \multirow{2}{*}{$6.810^{*}$} & \multirow{2}{*}{0.0115} \\
\hline & & Female & 8.46 & & \\
\hline \multirow{2}{*}{6} & \multirow{2}{*}{ Social support } & Male & 6.2 & \multirow{2}{*}{$7.675^{* *}$} & \multirow{2}{*}{0.0075} \\
\hline & & Female & 7.7 & & \\
\hline \multirow{2}{*}{7} & \multirow{2}{*}{ Primary group concern } & Male & 5.83 & \multirow{2}{*}{$6.373^{*}$} & \multirow{2}{*}{0.0143} \\
\hline & & Female & 4.06 & & \\
\hline \multirow{2}{*}{8} & \multirow{2}{*}{ Inadequate mental mastery } & Male & 14.06 & \multirow{2}{*}{$4.623^{*}$} & \multirow{2}{*}{0.0357} \\
\hline & & Female & 15.93 & & \\
\hline \multirow{2}{*}{9} & \multirow{2}{*}{ Perceived ill-health } & Male & 13.56 & \multirow{2}{*}{$5.327 *$} & \multirow{2}{*}{0.0245} \\
\hline & & Female & 15.13 & & \\
\hline \multirow{2}{*}{10} & \multirow{2}{*}{ Deficiency in social contacts } & Male & 6.1 & \multirow{2}{*}{$4.520^{*}$} & \multirow{2}{*}{0.0377} \\
\hline & & Female & 7.03 & & \\
\hline \multirow{4}{*}{11} & \multirow{2}{*}{ General well-being-negative affect } & Male & 7.4 & \multirow{2}{*}{$5.679 *$} & \multirow{2}{*}{0.0204} \\
\hline & & Female & 8.26 & & \\
\hline & \multirow{2}{*}{ Total SWB } & Male & 86.6 & \multirow{2}{*}{$0.431 \mathrm{NS}$} & \multirow{2}{*}{0.4310} \\
\hline & & Female & 89 & & \\
\hline
\end{tabular}

The results of the above table, indicating the differences in mean scores of subjective well-being dimensions arranged, according to the gender. It was evident from the results that, there were significant differences noticed in mean scores of both men and women, with reference to the dimensions viz. general well-being, positive effect, expectationachieve congruence, confidence in coping, family group support, social support, inadequate mental mastery, perceived illhealth, deficiency in social contacts and general well-being-negative effect.

On the dimension of general well-being, positive effect, expectation-achievement congruence men had a higher mean score, than women. The reason could be, men have a more positive attitude towards their future and they might have high aspirations in career, than women. Further, men might have more feelings of well-being generated by achieving the standard of living, social status, success and freedom as per one's expectations or what may be called satisfactory.

On the other dimensions, such as confidence in coping, family group support, social support men had a low mean score than women. This indicates women are receiving high family and social support than men. This might be, due to the reasons that, from the beginning women are protected by the family members, irrespective of their age, due to safety, whereas, men had given much freedom to take decisions on their own.

The dimension of inadequate mental mastery, perceived ill-health, and women had a higher mean score than men. This indicates, women had higher problems in these areas. This might be due to the reasons that, during these days we can find more of dual-earning families. For both men and woman's career is very important. Further, the married and working women have to play many roles at work place and at home. Each task demands her attention and all these roles sometimes create lots of stress and may lose emotional balance, often. Hence, all these factors might influence the women's subjective well-being in these domains.

The dimensions, deficiency in social contacts and general well-being-negative effect, women had a higher mean score. The reason could be, women getting into new marital relationships and they may feel about missing family and friends or worrying about being disliked. 


\section{CONCLUSIONS}

Subjective well-being, refers to how people evaluate their lives and includes variables such as life satisfaction, environmental mastery, lack of depression, anxiety and positive moods. The needs, problems and adjustment patterns may vary according to their age, socioeconomic status, health and living status. The aim of the current study was, to understand the subjective well-being of young adults in terms of age group and gender. The results showed that, there were age wise significant differences in mean scores of totally subjective-well being. The age group 26-30 years had higher subjective well-being, than the other age groups. There were no significant differences in means of both men and women, in relation to total subjective well-being.

\section{REFERENCES}

1. Dolan, P and R. Metcalfe. 2011. Comparing Measures of Subjective Well-Being and Views about the Role They Should Play in Policy. London, UK: Office for National Statistics. ONS, UK. 2011. "Findings from the National Well-Being Debate”, UK Office for National Statistics Paper, July 2011.

2. Grimes, A., Oxley, L and Tarrant, N. 2012. "Does Money Buy Me Love? Testing Alternative Measures of National Wellbeing." Motu Working Paper 12-09, Motu Economic and Public policy Research.

3. De Neve, J.-E., E. Diener, L. Tay, and C. Xuereb (2013), "The Objective Benefits of Subjective Well-Being”, in J. F. Helliwell, R. Layard, and J. Sachs (Eds.) (2013) World Happiness Report 2013. New York: UN Sustainable Development Solutions Network

4. Diener, E. And M. Chan. 2011. "Happy people live longer: Subjective well-being, contributes to health and longevity", Applied Psychology: Health and Well-Being, Vol.3, pp. 1-43.

5. Lyubomirsky, S., L. King and Diener, E. 2005. "The Benefits of Frequent Positive Affect: Does Happiness Lead to Success?" Psychological Bulletin, Vol. 131 (6), pp. 803-855.

6. New Economics Foundation (2009), “A guide to measuring children's well-being. Booking the Future: Practical Guide 2”, London, and 16 September.

7. http://www.oecdbetterlifeindex.org/blog/in-search-of-satisfaction.htm 